\title{
Thermal Analysis of the Performance of Linear Fresnel Solar Concentrator
}

\author{
Mohamed H. Ahmed and Amr M. A. Amin
}

\begin{abstract}
The Linear Fresnel Concentrator (LFC) took a significant attention in the recent decades from the researchers and the stakeholders. This attention can be attributed to possessing this type of concentrator several features enable it to overcome some of the problems facing other types of concentrators. Numerical simulation for the LFC along one year has been carried out for a given design. The results illustrate the effect of the Incidence Angle Modifier (IAM) and the operating parameters such as, the fluid mass flow rate and the inlet temperature on the thermal performance of the LFC. The results show a significant effect of the daily and seasonal changing in the incidence angle of the direct radiation on the IAM consequently the thermal performance and the collector efficiency. Maximum output thermal energy of about 40 to 96 KW was recorded for December and June respectively. This paper presents a numerical model that can be used for design optimization to get the maximum efficiency.
\end{abstract}

Index Terms-Incidence angle modifier, linear Fresnel concentrator, simulation model, receiver tube.

\section{INTRODUCTION}

Solar concentrators are one of the means of solar energy collecting for getting thermal energy at a high temperature. Despite the widespread of installing and operating a solar concentrator plant with the Parabolic Trough Collector (PTC) type compare to the Linear Fresnel Collector type LFC, there are many serious attempts to push the LFC to compete strongly in the solar concentrator market with the parabolic trough collector. This is due to the fact that linear Fresnel collectors have obvious economic advantages when compared to other technologies.

A linear Fresnel solar concentrator may have a lower efficiency than the other concentrating geometries, but the likely reduced cost may well compensate that, providing a solution for cost-effective solar energy collection on a large scale [1]. The advantages of linear concentrating Fresnel collectors include relatively simple construction, low wind loads, a stationary receiver and high ground usage [2]. Some applications allow the use of the shaded area underneath the collector (e.g. for parking lots) and supply basic needs to rural remote communities. The previous advantage and the low cost of the operation and maintenance (O\&M) lead to a

Manuscript received March 31, 2015; revised September 8, 2015. This work was funded and supported by the grant from the Academy of Scientific Research and Technology (ASRT) and from the European Neighborhood and Partnership Instrument (ENPI) through STS_MED project under grant agreement n. 268219.

M. H. Ahmed is with the Solar Energy Department, National Research Center, Dokki, Egypt (e-mail: mo555as@hotmail.com).

A. M. A. Amin is with the Electrical Department, Helwan University, Helwan, Egypt (e-mail: amrmaamin@yahoo.com). reduction in the Levelized Cost of Energy (LCOE) by about $11 \%$ relative to the PTC.

The Linear Fresnel Reflector (LFR) concept uses a set of long mirror facets that reflect light to a linear receiver where it can be directly absorbed by the receiver [3] or concentrated a second time with a compound parabolic reflector [4]. Singh carried out experiments to study the temperature of the working fluid and efficiency of solar energy to the net heat gained of the linear Fresnel reflector with different number of mirror elements [5].

The main weakness of LFRs is that the concentration factor achieved until now was notably lower than for PTCs, changing importantly along the day. However, Muñoz et al have proved that exergetic efficiency for the concentrations achieved by LFR is close enough to PTC efficiencies [6]. Most LFC were developed for low or medium-temperature heat generation [7]. For example, small-scale systems with heat output in the range of 150-300 C are suitable to be used in the heating/cooling of buildings [8], domestic water heating [9], steam generation for mining, textile and chemical industries, agriculture and timber and food applications [4]-[10].

Some of the main differences among LFC plants are based on the mirror aperture width, the tracking system design, the specific mirror's curvature (flat, circular or parabolic), the solar field filling factor, the height of the receiver above the primary mirror field and the detailed receiver design: multiple tube receiver or single-tube receiver.

The multi-tube design appears on the first prototypes and studies in LFC [11], [12]. The most conventional multi-tube design consists of a series of parallel tubes arranged horizontally in a cavity, usually with a trapezoidal cross-section and therefore without a secondary concentrator. A glass cover can be located at the opening of the cavity to protect the selective coating that decreases the emission losses. Another task for the glass cover is to make a greenhouse effect that benefits receiver performance. It also minimizes convection losses, due to the vacuum existing inside it.

The main fact that limits the concentration factor is the drift and uncertainty in the direction of the reflected rays, increased by the long distance between the mirrors and the receiver

\section{LFC GEOMETRIC}

The linear Fresnel collector consists of flat or nearly flat mirror to concentrate the direct sun radiation on an absorber tube located above the mirror filed. The incidence angle $\theta_{i}$ of the sunrays is divided into two angles as shown in Fig. 1: the transversal angle $\theta_{T}$ which is located between the Zenith and the projection of the direct sun ray into the transversal plane 
while the other angle is the longitudinal angle $\theta_{L}$ and is defined as the angle between the zenith and the and the projection of the direct sun ray into the longitudinal plane [13].

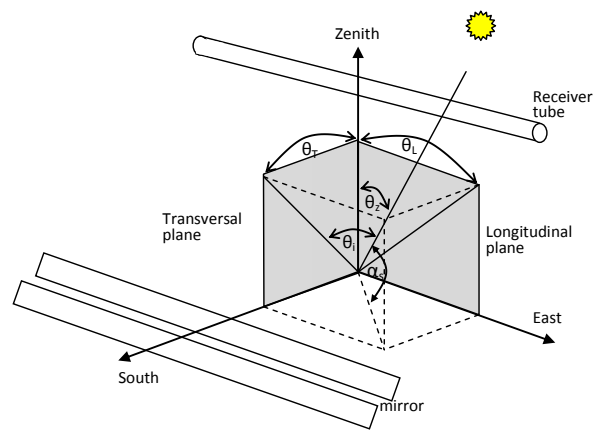

Fig. 1. The important angles of the linear Fresnel collector.

The net aperture area $A_{\text {net }}$ of the LFC collector is the sum of the net aperture area of all mirror row of the collector.

$$
A_{\mathrm{net}}=\sum_{i=1}^{n} W_{i} L
$$

where $W$ is the aperture width of the mirror row, $n$ is the number of the mirrors and $L$ is the mirror length.

\section{SimULATION MODEL}

In the simulation model, the effects of the operating parameters such as mass flow rate and the inlet fluid temperature of the Heat Transfer Fluid (HTF) were studied; also the performance of the collector through the first half of the year was studied. The mirror and receiver tube design parameters such as the mirror width and length, mirror curvature, the gap between mirror, the focal length of mirror row and the inner and outer diameter of the receiver of the LFC were included as fixed parameters. Also the optical material parameters (Reflectance, transmittance, emittance and absorptance.) were included in the model as shown in Table I.

The rate of energy incident to the receiver tube can be calculated from the following equation (According to EN 12975-2 [4] the thermal collector performance is described as):

$$
\dot{q}_{\text {input }}=A_{\text {net }} \times D N I \times \eta_{\text {otp }, p} \times I A M(\theta) \times E L F
$$

where, the DNI is the direct normal irradiance $\left(\mathrm{w} / \mathrm{m}^{2}\right)$. The peak optical efficiency $\eta_{o p t, p}$ depends on mirror reflectivity $\left(\rho_{m i}\right)$, glass cover transmissivity $\left(\tau_{g}\right)$ and the absorptivity $\left(\alpha_{c o}\right)$ of the selective coating of the absorber tube.

$$
\eta_{o t p, p}=\rho_{m i} \times \tau_{g} \times \alpha_{c o}
$$

The incidence angle modifier $\operatorname{IAM}\left(\theta_{i}\right)$ is approximated by multiplying the incidence angle modifier in the longitudinal direction $\operatorname{IAM}_{L}\left(\theta_{i}\right)$ with the incidence angle modifier in transversal direction $\operatorname{IAM}_{T}\left(\theta_{T}\right)$. Fig. 2 shows the variation of the $I A M_{L}$ and the $I A M_{T}$ for different incidence angle $\theta_{i}$.

$$
\operatorname{IAM}(\theta)=\operatorname{IAM}_{L}\left(\theta_{i}\right) \times \operatorname{IAM}_{T}\left(\theta_{T}\right)
$$

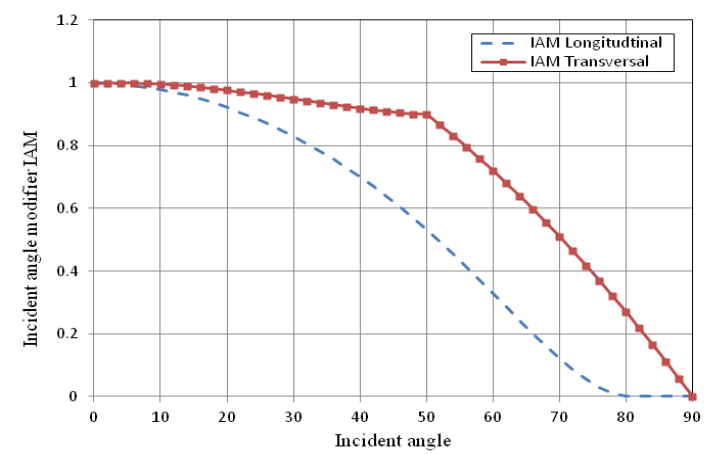

Fig. 2. The incidence angle modifier IAM in the transversal and longitudinal direction.

The useful receiver length of $L F C$ that receive the concentrated radiation is reduced by the effect of the incidence angle and can be expressed by the End Losses Factor $(E L F)$, which depend on the collector length $L$ and the focal length $F$.

$$
E L F=1-\frac{F / \tan \theta_{i}}{L}
$$

The focal length $F$ can be substituted by an effective focal length $F_{\text {eff }}$ for $L F C$ as shown in Fig. 3 [14].

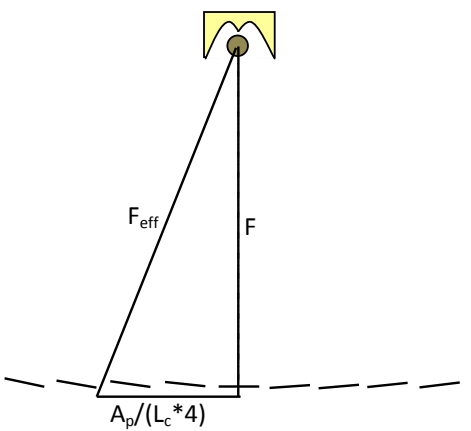

Fig. 3. The effective focal length for the LFC.

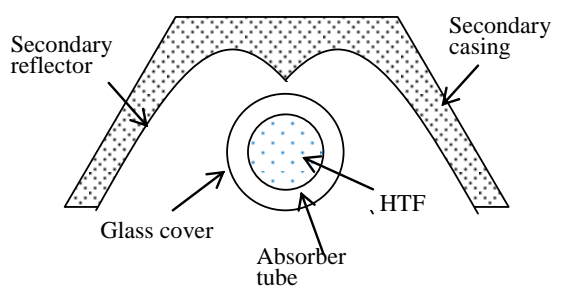

Fig. 4. The construction of the receiver tube assembly.

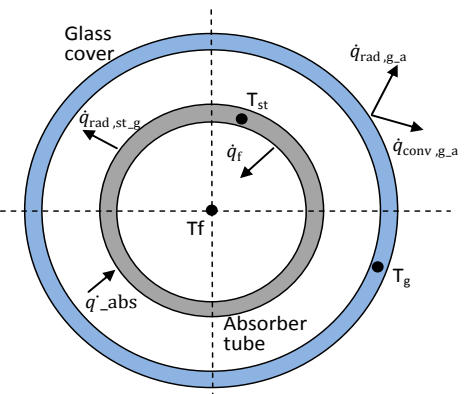

Fig. 5. The energy flow of the receiver tube. 
The receiver, consisting of secondary reflectors and vacuum absorber tubes as shown in Fig. 4. The outlet temperature of the HTF, which is synthetic oil in our study, can be calculated by solving the energy balance equations for the glass cover and absorber tube and the fluid flow in the receiver tube as shown in Fig. 5.

The energy balance equations per unit length for a small segment of length $d x$ for the heat transfer fluid, steel tube and the glass cover are as follow:

The energy balance for the heat transfer fluid.

$$
h_{c, s t-f}\left(T_{s, i}-T_{m s}\right) \pi D_{s t, i} d x-q_{i}+q_{o}=m_{f} C p_{f} \frac{\partial T_{f}}{\partial t}
$$

The energy balance for the absorber tube.

$$
\begin{aligned}
& \left(q_{a b s}-q_{r, s t-g}\right) \pi D_{s t, o} d-h_{c, s t-f}\left(T_{s t, i}-T_{f}\right) \\
& \times \pi D_{s t, i} d x=m_{s t} C p_{s t} \frac{\partial T_{s t}}{\partial t}
\end{aligned}
$$

The energy balance for the glass cover.

$$
\begin{aligned}
& q_{r, s t-g} \pi D_{s, o} d x+q_{a b s, g} \pi\left(r_{g, o}^{2}-r_{g, i}^{2}\right) d x \\
& -\left(q_{c, g-a}+q_{r, g-s k y}\right) d x=m_{g} C p_{g} \frac{\partial T_{g}}{\partial t}
\end{aligned}
$$

By solving the previous equations simultaneously using the Engineering Equation Solver (EES), the glass temperature $T_{g}$, absorber tube temperature $T_{s t}$ and the fluid temperature $T_{f}$ can be obtained. The outlet temperature of the oil fluid, which represents the HTF, is calculated from the following equation:

$$
T_{\text {out }}=2 \times T_{f}-T_{\text {in }}
$$

The power output from the receiver tube that is transferred to the synthetic oil can be calculated from the following equation.

$$
\dot{q}_{\text {out }}=\dot{m} \times C p \times\left(T_{\text {out }}-T_{\text {in }}\right)
$$

Thermal loss for the receiver tube $\dot{q}_{\text {loss }}$ is the difference between the input radiation power to the receiver tube and the thermal power gained by the oil $\dot{q}$ out

Some assumptions were taken into the considerations to maximize the simplicity of the analysis as the following:

1) Steady state condition during the small period of the sun movement.

2) Uniform temperature of the steel tube and the glass cover.

3) The temperature variant along the segment length is neglected (one- dimension).

4) The properties of the solid and fluid are a function of temperature.

5) As shown previously, an effective focal length was used for all mirror rows instead of a separately focal length for each row.

6) The flow inside the absorber tube is fully developed.

TABLE I: THE PARAMETER USED IN THE MODELING

\begin{tabular}{lll}
\hline \hline Design parameter of LFC & value & unit \\
\hline Inner absorber tube diameter & 0.066 & $\mathrm{~m}$ \\
Outer absorber tube diameter & 0.07 & $\mathrm{~m}$ \\
Mirror width & 0.31 & $\mathrm{~m}$ \\
No. of mirror row & 18 & \\
Center focal length & 3.564 & $\mathrm{~m}$ \\
Module length [m] & 4 & $\mathrm{~m}$ \\
No. of module & 12 & \\
Internal diameter of glass cover & 0.1 & $\mathrm{~m}$ \\
External diameter glass cover & 0.106 & $\mathrm{~m}$ \\
Receiver coating absorbance & 0.958 & \\
Glass cover transmittance & 0.964 & \\
\hline \hline
\end{tabular}

\section{NUMERICAL RESUlT UNITS}

The numerical results of the simulation program are presented in the following part. One of the most important parameter that affects the LFC is the incidence angle modifier. Our model can predict this value through a day length based on an experimental data. The incidence angle modifier through a day for December, March and Jun are shown in Fig. 6. The incidence angle increase sharply in the early morning and late evening for all months. Around solar noon, the incidence angle modifier has the highest value where it ranges from 0.9 to 1 for June, while it has the lowest value at solar noon for December, where it ranges from 0.46 to 0.55 . We can also observe stability in the IAM for March mean while we can observe a variant in the IAM for December and June at solar noon.

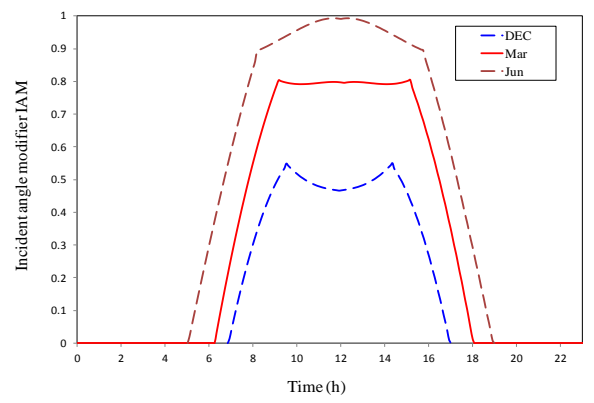

Fig. 6. The incidence angle on the LF mirror.

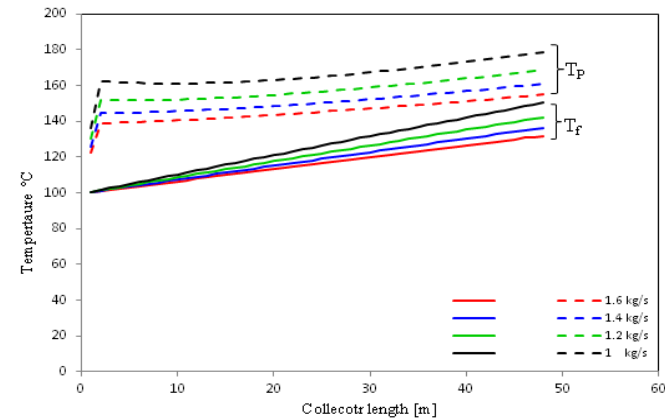

Fig. 7. The effect of the mass flow rate on the tube and fluid temperature.

The temperatures of the glass cover, absorber tube and the fluid flow were presented along the receiver tube length of the linear Fresnel collector at a different mass flow rate as shown in Fig. 7. From the figure, we can observe that, there is no 
significant increase in the temperature of the fluid and the absorber tube with increasing the mass flow rate above 1.2 $\mathrm{kg} / \mathrm{s}$. It seems that the influence of the mass flow rate on the fluid and the absorber tube temperature is small above 1.2 $\mathrm{kg} / \mathrm{s}$. The effect of the mass flow rate on the fluid temperature at the first part of the collector is unnoticeable while this effect becomes noticeable gradually with the progression of the fluid through the collector length.

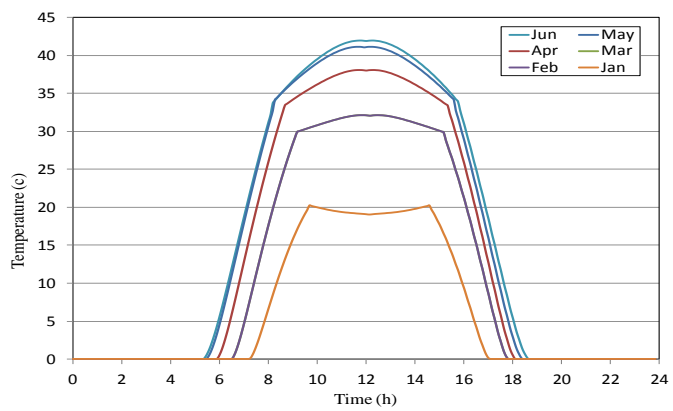

Fig. 8. The temperature rise of the LFC at different months.

The temperature rise $\Delta T$ for the LFC are presented through one day during the first six months of the year as shown in Fig. 8. The temperature rise has a value of $20^{\circ} \mathrm{C}$ around the solar noon during the January month. The small value of $\Delta \mathrm{T}$ can attribute to the higher incidence angle during this month, while it has a higher value during the next months, especially in the summer months where the temperature rise increases by about $110 \%$ from the value on December to reach $42^{\circ} \mathrm{C}$.

The rate of the thermal energy gained from the Linear Fresnel Collector for December, March and June are illustrated in Fig. 9. These months represent the winter, spring and summer in Cairo. We can observe that the rate of energy gained in June is higher than that of March and December. The maximum rate of thermal energy gained accrues at solar noon in June, while for December occurs 90 minutes before and after the solar noon. That can be attributed to the changing in the incidence angle profile during the day of these months. For all months, there is a sharp increasing and decreasing in the rate of energy gained in the early mooring and late evening as shown in the figure which can be attribute to the profile of the incidence angle modifier IAM as shown in Fig. 6. During solar noon period, there is a variant in the rate of energy gained by about 20\%, 5\% and $10 \%$ for June, March and December, respectively. From the previous observation, we can conclude that the rate of output energy from the linear Fresnel collector LFC is more stable in the spring and autumn months but it has significant variations for the summer months.

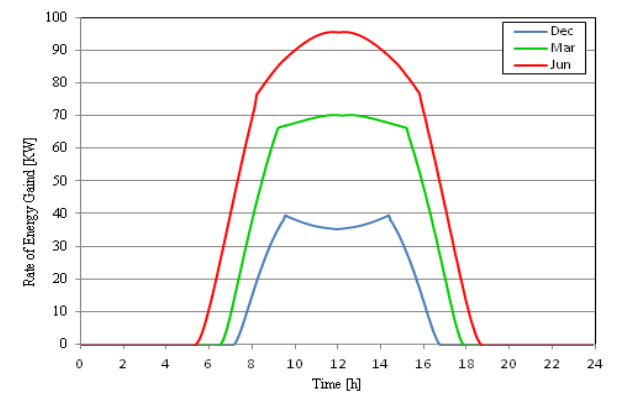

Fig. 9. The rate of output energy gained from the LFC at December, Maras and Jun months.
The effects of the inlet temperature of heat transfer fluid on the fluid temperature rise through the LFC are shown in Fig. 10. From the figure we can observe that increasing the inlet temperature from 80 to $200^{\circ} \mathrm{C}$ leads to decreasing in the temperature rise by about $12 \%$ for all ranges of mass flow rate that under investigation. While, increasing the flow rate from 0.9 to $1.3 \mathrm{~kg} / \mathrm{s}$ leads to a decreasing in the temperature rise by about $30 \%$.

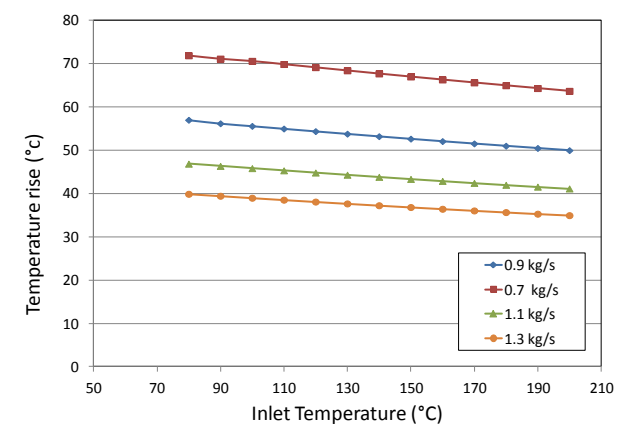

Fig. 10. Effect of the inlet temperature on the fluid temperature raise.

Also the effect of the inlet temperature on the efficiency of the LFC is illustrated in Fig. 11 at different mass flow rate. A slight increase in the efficiency from 47.7 to $48.3 \%$ was recorded during increasing the mass flow rate from 0.7 to 1.3 $\mathrm{kg} / \mathrm{s}$ at all inlet temperatures.

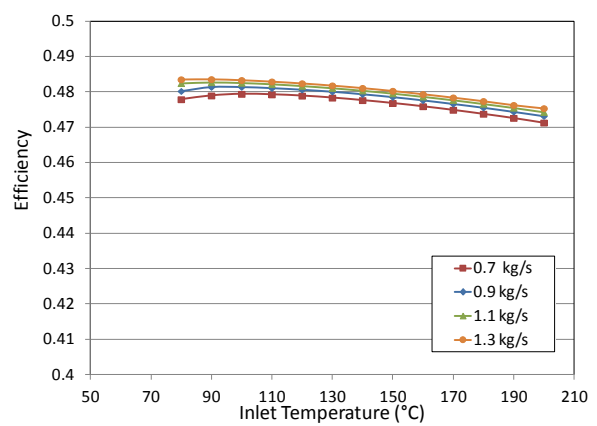

Fig. 11. Effect of the inlet temperature on the LFC efficiency.

\section{CONClusion}

From the previous results, we can conclude that, the effect of the incidence angle has a significant role in the incidence angle modifier and the incidence ration on the absorber receiver tube. The IAM has the best value of about 0.9 to 1 around solar noon in Jun and a lowest value of 0.46 to 0.55 in December. At solar noon, the temperature rise ranges from 20 to $42^{\circ} \mathrm{C}$ for December and Jun, respectively. The other conclusion from the theoretical study is that the rate of energy gained is very small at the early morning and late evening and increase sharply to reach nearly the stable value around the solar noon. But in the summer months the stability of the rate of energy gained is low. The effect of inlet fluid temperature on the temperature rise and collector efficiency is smaller compared to the effect of the fluid mass flow rate.

\section{APPENDIX}

Nomenclature

A: $\quad$ Area $\left(\mathrm{m}^{2}\right)$

Cp: $\quad$ Specific heat 


$\begin{array}{ll}D: & \text { Diameter }(\mathrm{m}) \\ F: & \text { Focal length }(\mathrm{m}) \\ L: & \text { Mirror length }\left(\mathrm{m}^{2}\right) \\ m: & \text { mass }(\mathrm{kg}) \\ h: & \text { heat transfer coefficient }\left(\mathrm{W} / \mathrm{m}^{2}{ }^{\circ} \mathrm{C}\right) \\ \dot{m}: & \text { Mass flow rate }(\mathrm{kg} / \mathrm{s}) \\ \dot{q}: & \text { Rate of energy }(\mathrm{W}) \\ T: & \text { Temperature }\left({ }^{\circ} \mathrm{C}\right) \\ t: & \text { Time }(\mathrm{s}) \\ W: & \text { Mirror width }\left(\mathrm{m}^{2}\right) \\ \theta: & \text { Incidence angle } \\ \eta: & \text { Efficiency } \\ \rho: & \text { Reflectivity } \\ \tau: & \text { Transmissivity } \\ \alpha: & \text { Absorptivity } \\ \text { Subscripts } \\ a: & \text { Ambient } \\ a b s: & \text { absorbed } \\ i: & \text { Inside } \\ o: & \text { Outside } \\ i n: & \text { Inlet } \\ o u t: & \text { Outlet } \\ c: & \text { Heat transfer by convection } \\ s t & \text { Steel tube } \\ f: & \text { Fluid } \\ g: & \text { Glass } \\ r: & \text { Heat transfer by radiation } \\ & \end{array}$

\section{ACKNOWLEDGMENT}

The authors are grateful to the ASRT and the European Neighbourhood and Partnership Instrument (ENPI) and also to the Consorzio ARCA research center (Palermo, Italy,) for submitting the required data.

\section{REFERENCES}

[1] D. Buie, C. Dey, and D. Mills, "Optical considerations in line focus Fresnel concentrators," in Proc. 11th International Solar Paces Conference, Zurich, Switzerland, 2002.

[2] A. Häberle et al., "Linear concentrating Fresnel collector for process heat applications," in Proc. 13th International Symposium on Concentrated Solar Power and Chemical Energy Technologies, Sevilla, Spain, 2006.

[3] D. R. Mills and G. L. Morrison, "Compact linear Fresnel reflector solar thermal power plants," Solar Energy, vol. 68, no. 3, pp. 263-283, 2000.

[4] G. Morin, M. Mertins, J. Kirchberger, and M. Selig, "Supernova construction, control \& performance of steam superheating linear fresnel collector," in Proc. 2011 Solar PACES International Symposium, 2011, pp. 1-6.

[5] P. L. Singh, S. Ganesan, and G. C. Yadav, "Performance study of a linear fresnel concentrating solar device," Renewable Energy Focus, vol. 18, pp. 409-416, 1999.

[6] J. Muñoz, J. M. Martınez-Val, and A. Ramos, "Thermal regimes in solar-thermal linear collectors," Solar Energy, vol. 85, no. 5, pp. 857-870, 2011.
[7] G. Zhu, "Development of an analytical optical method for linear Fresnel collectors," Solar Energy, vol. 94, pp. 240-252, 2013.

[8] P. Bermejo, F. J. Pino, and F. Rosa, "Solar absorption cooling plant in Seville," Solar Energy, vol. 84, no. 8, pp. 1503-1512, 2010

[9] T. Sultana, G. L. Morrison, and G. Rosengarten, "Thermal performance of a novel rooftop solar micro-concentrating collector," Solar Energy, vol. 86, no. 7, pp. 1992-2000, 2012

[10] J. Rawlins and M. Ashcroft. Small scale concentrated solar power-A review of current activity and potential to accelerate employment -Report. Carbon Trust 2013. [Online]. Available: https://www.gov.uk/government/uploads/system/uploads/attachment_ data/file/191058/small_scale_concentrated_solar_power_carbon_trus t.pdf

[11] G. Francia, "Pilots plants of solar steam generating stations," Solar Energy, vol. 12, pp. 51-64, 1968

[12] G. D. Canio, W. J. Treytl, F. A. Jur, and C. D. Watson, "Line focus solar thermal central receiver research study-final report," US Department of Energy, Santa Clara, CA, 1979.

[13] M. Mertins, "Technical and economic analysis of horizontal Fresnel collectors," Ph.D. thesis, Karlsruhe University, Germany, 2009.

[14] A. Heimsath, G. Bern, D. van Rooyen, and P. Nitz, "Quantifying optical loss factors of small linear concentrating collectors for process heat application," Energy Procedia, vol. 48, pp. 77-86, 2014

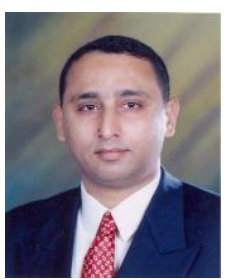

Mohamed H. Ahmed was born in January 1968 , Cairo, Egypt. He received the B.Sc. degree in mechanical power engineering from the Faculty of Engineering, Cairo University in 1990 . He received the M.Sc. degree and the Ph.D. degree in mechanical power engineering (heat transfer \& solar energy) from the Faculty of Engineering, Cairo University in 1997 and 2003, respectively.

$\mathrm{He}$ is an associate professor in Solar Energy Departments National Research Center, Giza, Egypt and he works as a researcher. His research includes solar drying, cooling, energy storage and solar thermal power plant.

Dr. Ahmed published six papers in international journals in the solar energy field and published two papers in international conferences and has experiences in renewable energy, thermal application of solar energy, solar concentrators and modeling and simulation.

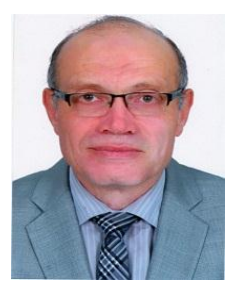

Amr M. A. Amin received the B.Sc. degree in electrical engineering from Helwan University, Cairo, Egypt, in 1978, the M.Sc. degree in electrical engineering and the Ph.D. degree in electrical and computer engineering from New Mexico State University, Las Cruces, in 1982 and 1986, respectively.

Since 2000, he has been a full professor in the Department of Electrical Machines and Power Engineering, Faculty of Engineering, Helwan University. He served as the vice dean and dean of the Faculty of Engineering, Helwan University and the dean of the Higher Technological Institute- $10^{\text {th }}$ of Ramadan, Egypt. His current research interests include renewable energy resources, power systems, electric drives, power electronics, electric drives, computer-based controllers, computer simulation, artificial intelligence, automatic control, and e-learning management systems. He has over 50 publications in refereed journals and conferences.

Dr. Amin is currently involved in several funded research projects. Those include solar energy water desalination, 400K euro RDI fund and CSP prototype for $1 \mathrm{MW}$ electricity generation and water desalination, 22M euro FP7 fund, and STS-MED small scale thermal district units for Mediterranean communities, 5 Meuro, EU-ENPI program. Dr. Amin was granted many educational and research awards. He served as a reviewer for many national and international funding schemes, FP7, TEMPUS, RDI, IMC and STDF. 